\title{
Simultaneous Determination of Atorvastatin and Amlodipine in Industrial Tablets by Apparent Content Curve and HPLC Methods
}

\author{
Imre Silvia, Kacsó Klára, Muntean Daniela-Lucia \\ Department of Drug Analysis, Faculty of Pharmacy, University of Medicine and Pharmacy, Tîrgu Mureș, Romania
}

\begin{abstract}
Introduction: This study proposes the simultaneous determination of atorvastatin and amlodipine in industrial tablets by a quantitative spectrophotometric method, named the apparent content curve method, test method, and by an HPLC method with UV detection as reference method.

Materials and methods: A synthetic mixture and two fixed medicinal combinations containing amlodipine and atorvastatin were investigated by the apparent content curve method, a simple and relatively inexpensive UV-VIS spectrophotometric method based on a mathematical approach derived from the Lambert-Beer law. The results were compared with those obtained by an HPLC method.

Results: A good correlation of the results was obtained, the difference between the pair results was not significant $(p>0.05)$.

Conclusions: The proposed spectrophotometric method is an easier and cheaper alternative for the quantitative determination of amlodipine and atorvastatin in industrial fixed-dose combinations.
\end{abstract}

Keywords: apparent content curve, UV spectrophotometry, HPLC, atorvastatin, amlodipine

Received: 27 October 2012

\section{Introduction}

The fixed combination of amlodipine (AML) and atorvastatin (AT) simultaneously reduces both blood pressure and lipid levels, with prevention of cardiovascular diseases $[1,2,3]$. AML is a dihydropyridine calcium channel blocker and inhibits the extracellular calcium influx into vascular smooth muscle. The consequence is muscle relaxation and vascular dilatation, and for this reason it is used to treat hypertension, angina or coronary heart disease. AT is a competitive inhibitor of HMG-CoA reductase, reducing LDL cholesterol, apolipoprotein $\mathrm{B}$ and triglycerides, and increasing HDL cholesterol in the treatment of hyperlipidaemia, when associated with a proper diet and exercise.

Several techniques, including chemometric methods [4,5,6], RP-HPLC [7] and HPLC methods [8] have been employed for the simultaneous determination of AT and AML from fixed combinations.

This study attempts to demonstrate the usefulness and ability of spectrophotometry in the analysis of multicomponent pharmaceutical systems [9]. At first, spectral behavior of AML and AT was studied for their quantitative spectrophotometric determination. Then, the apparent content curve (ACC) method was applied for the simultaneous determination of both substances in industrial tablets [10]. Since the ACC method is considered a secondary method, quantitative determination was also performed by HPLC method, considered as a reference method. The results obtained in these studies are discussed and compared.

Correspondence to: Daniela Lucia Muntean

E-mail: danielaluciamuntean@yahoo.com

\section{Materials and methods}

\section{Chemicals and reagents}

The reference substances were AML besylate, working standard provided by Gedeon Richter Romania, AT calcium trihydrate, working standard provided by Synfine. Methanol (Merck) and ultrapure water (Millipore) were used for the ACC method, and acetonitrile, potassium dihydrogen phosphate, methanol (Merck) and ultrapure water (Millipore), for the HPLC method.

\section{Tested pharmaceutical products}

Two types of commercial products were tested: product 1 - tablets containing the equivalent of $5 \mathrm{mg}$ AML as AML besylate and the equivalent of $10 \mathrm{mg}$ AT as AT calcium trihydrate; product 2 - tablets containing the equivalent of $10 \mathrm{mg}$ AML as AML besylate and the equivalent of $10 \mathrm{mg}$ AT as AT calcium trihydrate.

\section{Instruments}

For spectrophotometric determinations, UV-1601 UVVIS spectrophotometer (Shimadzu, Japan) provided with $1 \mathrm{~cm}$ quartz cells was used. The HPLC analysis was performed with a 1100 HPLC system with UV detection, producer Agilent Technologies (USA), equipped with Luna C18 column $(150 \times 4.6 \mathrm{~mm}, 3 \mu \mathrm{m}$, Phenomenex).

\section{Procedures}

a) The ACC method

The method has been extensively described previously 
since it was first published [10] and the same notation has been used in the present study.

\section{Determination of molar absorption coefficient and the se-} lection of the working wavelengths

In order to determine the molar absorption coefficients of AML besylate and AT calcium in methanol, a standard solution of $10 \mu \mathrm{g} / \mathrm{ml}$ AML in methanol and a standard solution of $20 \mu \mathrm{g} / \mathrm{ml}$ AT in methanol were prepared, starting from stock methanol solutions of $100 \mu \mathrm{g} / \mathrm{ml}$ AML and $200 \mu \mathrm{g} / \mathrm{ml} \mathrm{AT}$, respectively. Spectra were recorded on both standard solutions in the $200-400 \mathrm{~nm}$ field, using $1 \mathrm{~cm}$ quartz cuvettes. By taking into account the mathematical expression of the Lambert-Beer law, the molar absorption coefficients at different wavelengths were obtained.

From two stock solutions of AT calcium and AML besylate with concentrations of $200 \mu \mathrm{g} / \mathrm{ml}$ and $100 \mu \mathrm{g} / \mathrm{ml}$ respectively, a standard mixture of AT and AML with concentrations of $10 \mu \mathrm{g} / \mathrm{ml} \mathrm{AT}$ and $5 \mu \mathrm{g} / \mathrm{ml} \mathrm{AML}$ in methanol was obtained. The spectra of the obtained standard mixture was recorded and it allowed the building of apparent content curve $F=f(\lambda)$. The term $F$ is called apparent content being $\mathrm{F}_{\lambda}=\left(\mathrm{A} / \varepsilon_{\mathrm{A}}\right)_{\lambda}=\mathrm{c}_{\text {apparent, }}$, where $\mathrm{A}$ is the total absorbance of the solution at the wavelength $\lambda$ and $\varepsilon_{\mathrm{A}}$ is the molar absorption coefficient of the substance considered as analyte in the mixture. If there is any interference, the apparent content graphic is a curve line in the spectral interference domain. AT was chosen as analyte and AML as interferent, since in the studied industrial tablets we can find AT in equal or greater concentration than AML. The three working wavelengths $\lambda_{1}, \lambda_{2}$ and $\lambda_{3}$ were chosen from apparent content curve around the maximum absorption of the analyte, where the interference is strong. The differences between consecutive wavelengths have to be not more than $5 \mathrm{~nm}$.

\section{Construction of $R_{p}^{i}$ resolution calibration curves}

An initial standard binary mixture solution of $10 \mu \mathrm{g} / \mathrm{ml}$ AT and $10 \mu \mathrm{g} / \mathrm{ml}$ AML in methanol has been prepared from stock solutions of AML and AT, and a series of solutions were prepared by diluting the initial standard. After measuring the absorbances of these solutions on $\lambda_{1}, \lambda_{2}$ and $\lambda_{3}$, the value of qualitative parameter $\mathrm{Q}=\left(\mathrm{F}_{\lambda 1}-\mathrm{F}_{\lambda 2}\right) /$ $\left(\mathrm{F}_{\lambda 1}-\mathrm{F}_{\lambda 3}\right)$ could be calculated and the $\mathrm{R}_{\mathrm{p}}^{\mathrm{i}}=\mathrm{f}(1 / \mathrm{i})$ resolution calibration curve obtained. The term $\mathrm{R}$ is called resolution of the binary mixture:

$$
\mathrm{R}_{\mathrm{p}}=\mathrm{F}_{\lambda 1}-\mathrm{F}_{\lambda 3}=\left[\frac{\mathrm{A}}{\varepsilon_{\mathrm{A}}}\right]_{\lambda 1}-\left[\frac{\mathrm{A}}{\varepsilon_{\mathrm{A}}}\right]_{\lambda 3}
$$

For a series of standard mixture solutions $\mathrm{R}_{\mathrm{p}}$ is a linear function with the degree of dilution $1 / \mathrm{i}$. Of course, the quantitative ratio of the two substances in each standard solution in this series is the same.

The same procedure was applied for both control sample (standard mixture) and tablets samples.

\section{Determination of $A T$ and $A M L$ concentration}

A. Control sample analysis

A control sample solution with concentration $9 / 9 \mu \mathrm{g} / \mathrm{ml}$ AML/AT was obtained, and the absorbance was measured at the three selected wavelengths. Values of $Q_{x}$ and $R_{x}$ of the control sample were calculated and it was found the degree of dilution $1 / i$ of the initial standard mixture which can produce a new standard mixture with $\mathrm{R}_{\mathrm{p}}=\mathrm{R}_{\mathrm{x}}$ and it has a concentration of interferent $\mathrm{C}_{\mathrm{I}}$ equal with the concentration of interferent in the control sample $\left(\mathrm{C}_{\mathrm{I}}\right)_{\mathrm{x}}$. The control sample solution and the new standard mixture solution were diluted (degree $1 / \mathrm{j})$ in the same way, and the $F_{p}{ }^{j}=f(1 / j)$ and $F_{x}{ }^{j}=f(1 / j)$ curves were obtained, at $250 \mathrm{~nm}$. The difference between the slopes of the obtained lines, a and ax, allowed the calculation of AT (analyte) concentration:

$$
\left(\mathrm{C}_{\mathrm{A}}\right)_{\mathrm{x}}=\left(\mathrm{C}_{\mathrm{A}}\right)_{\mathrm{p}}-\left(\mathrm{a}-\mathrm{a}_{\mathrm{x}}\right)
$$

\section{B. Tablets analysis}

Extraction from tablets: 10 tablets were weighed accurately and ground into a fine powder. An accurately weighed amount of the powdered tablets equivalent to $5 \mathrm{mg}$ or 10 $\mathrm{mg}$ AML and $10 \mathrm{mg}$ AT was transferred into a $100 \mathrm{ml}$ standard flask and shaken with a mixture of methanol and ultrapure water $(9: 1)$ for 20 minutes in the ultrasonic bath, then made up to the mark with the solvent and mixed. The obtained solution was centrifuged for 5 minutes at 10,000 $\mathrm{rpm}$ at room temperature and then filtered through 0.45 $\mu \mathrm{m}$ PTFE filter. The filtrate was appropriately diluted with the respective solvent to obtain stock solutions of $50 \mu \mathrm{g} / \mathrm{ml}$ AML and $100 \mu \mathrm{g} / \mathrm{ml}$ AT for tablets 5/10, and $100 \mu \mathrm{g} / \mathrm{ml}$ AML and $100 \mu \mathrm{g} / \mathrm{ml}$ AT for tablets 10/10. After that, the sample stock solutions were diluted as follows: in the case of tablets $5 / 10$, a sample solution containing theoretically $6 / 12 \mu \mathrm{g} / \mathrm{ml} \mathrm{AML/AT} \mathrm{(sample} \mathrm{P1)} \mathrm{was} \mathrm{analysed,} \mathrm{and} \mathrm{in} \mathrm{the}$ case of tablets $10 / 10$, a sample solution with ratio concentration of $9 / 9 \mu \mathrm{g} / \mathrm{ml}$ AML/AT (sample P2).

In order to determine the working wavelengths, the ACC was obtained by using samples P1 and P2. After that, the procedure was the same as in the case of control sample.

\section{b) The HPLC method}

The optimized HPLC conditions were: column - Luna C18 (Phenomenex), $150 \times 4.6 \mathrm{~mm}, 3 \mu \mathrm{m}$; mobile phase - $10 \mathrm{mM}$ potassium dihydrogen phosphate solution (A) and acetonitrile (B); composition gradient - 0-5 $\min 40 \%$ B, 5-6 min $40 \rightarrow 60 \%$ B, 6-11 min $60 \%$ B, 11-12 min $60 \rightarrow 40 \%$ B, $12-15$ min $40 \%$ B; mobile phase flow -1 $\mathrm{ml} / \mathrm{min}$; column temperature $-30^{\circ} \mathrm{C}$; injection volume $10 \mu \mathrm{l}$; detector wavelength $-240 \mathrm{~nm}$.

\section{Results and Discussions}

As it is shown in Figures 1 and 2, the two substances have a significant spectral interference around $240 \mathrm{~nm}$ wavelengths. As working wavelengths were selected the follow- 


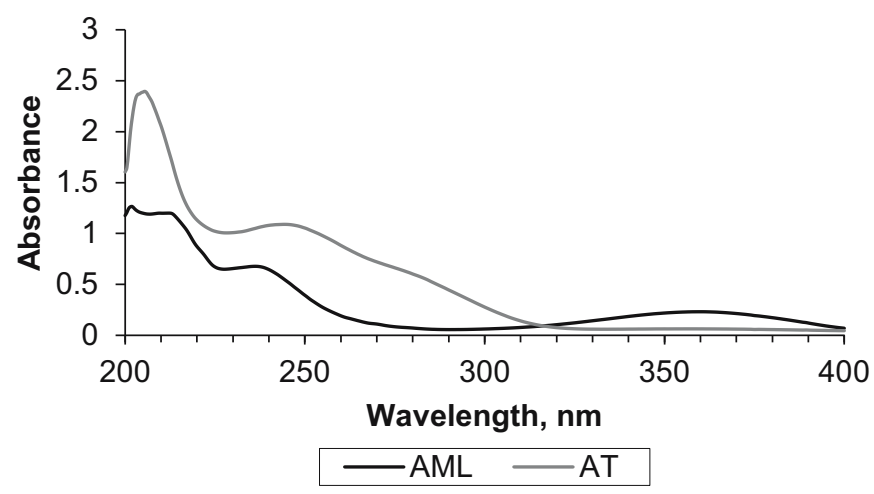

Fig. 1. Overlapped spectra of AML $(10 \mu \mathrm{g} / \mathrm{ml})$ and $A T(20 \mu \mathrm{g} / \mathrm{ml})$ in methanol

Table I. Values of $Q$ and $R$ for standard calibration mixtures used for quantitative determination of control sample (working wavelengths 245,250 and $255 \mathrm{~nm}$ )

\begin{tabular}{lccccc}
\hline & $1 / \mathrm{i}$ & $\left(\mathrm{C}_{\mathrm{A}}\right)_{\mathrm{p}}[\mathrm{M}]$ & $\left(\mathrm{C}_{\mathrm{A}_{\mathrm{p}}}[\mathrm{M}]\right.$ & $\mathrm{Q}$ & $\mathrm{R}_{\mathrm{p}}{ }^{i}[\mathrm{M}]$ \\
\hline 1 & $2.70 \cdot 10^{-5}$ & $3.68 \cdot 10^{-5}$ & 0.52 & $5.74 \cdot 10^{-6}$ \\
0.8 & $2.16 \cdot 10^{-5}$ & $2.94 \cdot 10^{-5}$ & 0.55 & $4.64 \cdot 10^{-6}$ \\
& 0.6 & $1.62 \cdot 10^{-5}$ & $2.21 \cdot 10^{-5}$ & 0.55 & $3.50 \cdot 10^{-6}$ \\
& 0.4 & $1.08 \cdot 10^{-5}$ & $1.47 \cdot 10^{-5}$ & 0.52 & $2.32 \cdot 10^{-6}$ \\
$\mathrm{Q}_{\text {mean }}$ & 0.2 & $0.54 \cdot 10^{-5}$ & $0.73 \cdot 10^{-5}$ & 0.52 & $1.18 \cdot 10^{-6}$ \\
Equation & $\mathrm{Q}_{\text {mean }}=0.53(\mathrm{SD} 0.01)$ & & & \\
\hline
\end{tabular}

Table II. Values of $Q$ and $R$ for standard calibration mixtures used for quantitative determination of tablets samples (working wavelengths 250,252 and $255 \mathrm{~nm}$ )

\begin{tabular}{lccccc}
\hline $1 / \mathrm{i}$ & $\left(\mathrm{C}_{\mathrm{A}}\right)_{\mathrm{p}}[\mathrm{M}]$ & $\left(\mathrm{C}_{1}\right)_{\mathrm{p}}[\mathrm{M}]$ & $\mathrm{Q}$ & $\mathrm{R}_{\mathrm{p}}{ }^{\mathrm{i}}[\mathrm{M}]$ \\
\hline 1 & $2.69 \cdot 10^{-5}$ & $3.67 \cdot 10^{-5}$ & 0.43 & $2.07 \cdot 10^{-6}$ \\
0.8 & $2.15 \cdot 10^{-5}$ & $2.93 \cdot 10^{-5}$ & 0.44 & $1.75 \cdot 10^{-6}$ \\
& 0.6 & $1.61 \cdot 10^{-5}$ & $2.20 \cdot 10^{-5}$ & 0.42 & $1.18 \cdot 10^{-6}$ \\
& 0.4 & $1.07 \cdot 10^{-5}$ & $1.47 \cdot 10^{-5}$ & 0.42 & $0.81 \cdot 10^{-6}$ \\
$\mathrm{Q}_{\text {mean }}$ & 0.2 & $0.53 \cdot 10^{-5}$ & $0.73 \cdot 10^{-5}$ & 0.44 & $0.45 \cdot 10^{-6}$ \\
Equation & $\mathrm{Q}_{\text {mean }}=0.43(\mathrm{SD} 0.01)$ & & & \\
\hline
\end{tabular}

Table III. The degree of dilution of the initial standard mixtures and the values $Q$ and $R$ for the tested samples

\begin{tabular}{lccc}
\hline Solution & $\mathrm{Q}_{\mathrm{x}}$ & $\mathrm{R}_{\mathrm{x}}$ & $1 / \mathrm{i}$ \\
\hline Control sample & 0.52 & $3.51 \cdot 10^{-6}$ & 0.6 \\
Sample P1 & 0.44 & $0.64 \cdot 10^{-6}$ & 0.31 \\
Sample P2 & 0.44 & $0.74 \cdot 10^{-6}$ & 0.35 \\
\hline
\end{tabular}

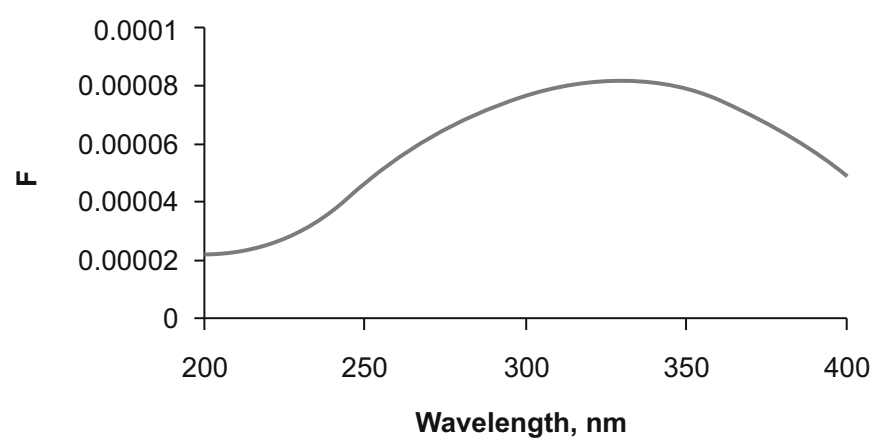

Fig. 2. Apparent content curve of a standard mixture of $A M L$ and AT (10 $\mu \mathrm{g} / \mathrm{ml}$ AT and $5 \mu \mathrm{g} / \mathrm{ml}$ AML), AT-analyte

ing two triples: a) 245,250 and $255 \mathrm{~nm}$ for control sample analysis; b) 250, 252 and $255 \mathrm{~nm}$ for tablets analysis. The slight differences between the working wavelenghts for the two type of samples were due to the apparently important interferences from disolved excipients at 200-240 nm.

Following the procedure described before, the results are summarized in Tables I-V.

The final results show that for the control sample we obtained experimental concentrations with relative errors under $1 \%$ against theoretical concentrations, which means that the ACC method is suitable for quantitative determination of this pair of substances in mixtures. For the 5/10 tablet sample the found that concentrations are below 3\% apart from nominal concentration, which means that the tablets are within acceptance limits of $\pm 7.5 \%$ provided by Pharmacopeia [11-13]. In the case of the 10/10 tablet the concentrations were obtained with a relative error of $5.6 \%$ for AT and $-15.6 \%$ for AML from nominal concentrations, the last being above the acceptance limits of $\pm 7.5 \%$.

The same solutions used for the ACC method were analyzed in parallel by the HPLC method. Under the discribed HPLC conditions, the two substances were separated with a good resolution (Figures 3 and 4).

The HPLC method was tested in terms of analytical performance as follows:

Specificity. As shown in the chromatograms, the method is specific for the determination of AT and AML from tablets, without any interference from the existing excipients in the tablets.

Linearity. Calibration curves were linear in the 3-15 $\mu \mathrm{g} /$ $\mathrm{ml}$ AML/AT range. The equations of the calibration curves for AML and AT are shown in Table VI.

Accuracy. The method proved to be accurate, the concentration of the standard solutions being recovered with a relative error less than $2 \%$.

Table IV. Parameters of the $F_{p}{ }^{j}$ and $F_{x}{ }^{j}$ equations

\begin{tabular}{|c|c|c|c|c|c|c|}
\hline \multirow[t]{2}{*}{ Equation parameters } & \multicolumn{2}{|c|}{ Control sample } & \multicolumn{2}{|c|}{ Sample P1 } & \multicolumn{2}{|c|}{ Sample P2 } \\
\hline & $\mathrm{F}_{\mathrm{p}}^{\mathrm{j}}$ & $F_{x}{ }^{j}$ & $F_{p}{ }^{j}$ & $F_{x}^{j}$ & $F_{p}{ }^{j}$ & $F_{x}{ }^{j}$ \\
\hline Intercept (b) & $-3.23 \cdot 10^{-6}$ & $-1.34 \cdot 10^{-6}$ & $-5.56 \cdot 10^{-7}$ & $-2.82 \cdot 10^{-6}$ & $-7.15 \cdot 10^{-7}$ & $-4.56 \cdot 10^{-7}$ \\
\hline Slope (a) & $2.586 \cdot 10^{-5}$ & $2.572 \cdot 10^{-5}$ & $1.393 \cdot 10^{-5}$ & $2.230 \cdot 10^{-5}$ & $1.447 \cdot 10^{-5}$ & $1.686 \cdot 10^{-5}$ \\
\hline $\mathrm{R}^{2}$ & 0.9998 & 0.998 & 0.9999 & 0.998 & 0.9996 & 0.9998 \\
\hline
\end{tabular}


Table V. Analyte and interferent concentrations in tested samples

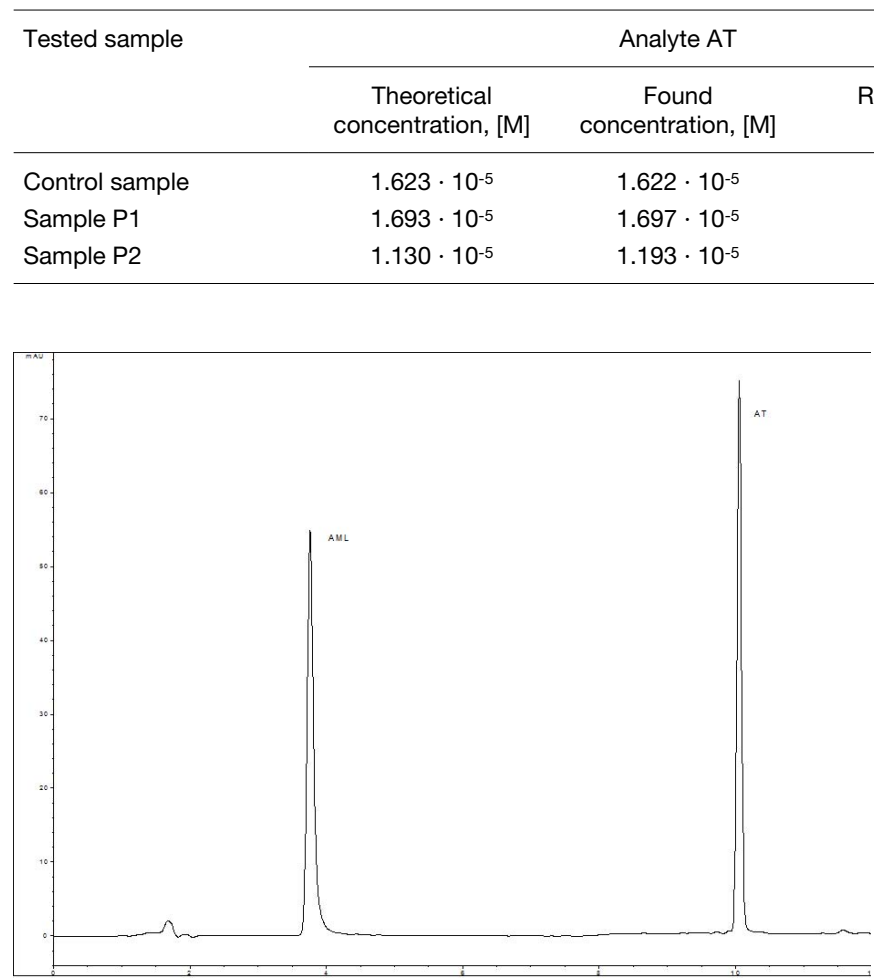

Fig. 3. Typical chromatogram - separation of $A M L\left(t_{R A M L}=3.79\right.$ $\mathrm{min}$ ) and $A T\left(t_{\mathrm{R} \mathrm{AT}}=10.08 \mathrm{~min}\right)$ from a standard methanolic solution containing $15 \mu \mathrm{g} / \mathrm{ml}$ of each substances

The final results of the determinations by HPLC method are shown in Table VII.

The results obtained from the two methods were compared (Table VIII). The differences, in terms of recovery, were less than $6 \%$ and not significant ( $p=0.31$ for AT and $\mathrm{p}=0.44$ for AML). The methods are comparable in terms of accuracy. The HPLC method has the advantage of being more sensitive and selective. On the other hand, the ACC method is easier, faster and cheaper.

\section{Conclusions}

The study is a new practical application of apparent content curve method. By comparing the results obtained by apparent content curve method with those obtained by ref-

Table VI. Equation parameters of the calibration curve for HPLC analysis

\begin{tabular}{lccc}
\hline Compound & Slope (a) & Intercept (b) & $\mathrm{R}^{2}$ \\
\hline AML & 25.36 & -2.54 & 0.9998 \\
AT & 22.80 & 1.84 & 0.9999 \\
\hline
\end{tabular}

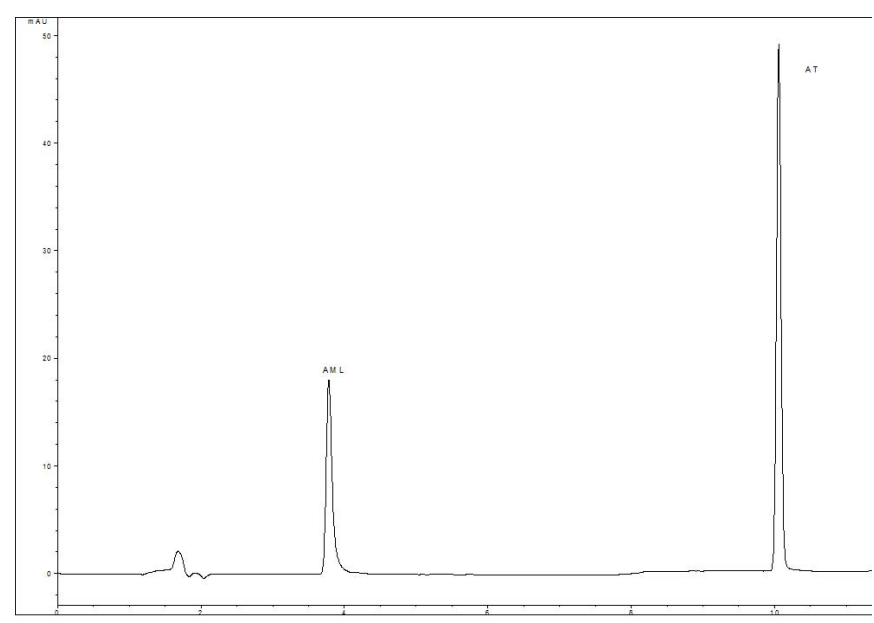

Fig. 4. Chromatogram of 5/10 AML/AT tablet sample

erence methods, in this case an HPLC method, we can say that the proposed spectrophotometric method is an easier and cheaper alternative for the quantitative determination of amlodipine and atorvastatin in industrial fixed-dose combinations. In comparison with other methods published regarding the simultaneous determination of the studied substances, the present method is able to provide accurate quantification without analytes separation, it is more understandable in comparison with more abstract chemometric or computational methods, and does not require spectra computation as in derivative spectrophotometry. Nevertheless, the method allows rapid qualitative analysis by a specific parameter.

Table VIII. Comparison of the results

\begin{tabular}{lcccc}
\hline Tested sample & \multicolumn{2}{c}{ Recovery AT \% } & \multicolumn{2}{c}{ Recovery AML $\%$} \\
\cline { 2 - 5 } & $\begin{array}{c}\text { ACC } \\
\text { method }\end{array}$ & $\begin{array}{c}\text { HPLC } \\
\text { method }\end{array}$ & $\begin{array}{c}\text { ACC } \\
\text { method }\end{array}$ & $\begin{array}{c}\text { HPLC } \\
\text { method }\end{array}$ \\
\hline Control sample & 99.9 & 102.0 & 100.8 & 101.4 \\
Sample P1 & 100.2 & 100.1 & 97.5 & 93.0 \\
Sample P2 & 105.6 & 99.3 & 84.4 & 87.2 \\
\hline
\end{tabular}

Table VII. HPLC results for tested samples

\begin{tabular}{lcccc}
\hline Tested sample & \multicolumn{2}{c}{ Analyte AT } & \multicolumn{2}{c}{ Interferent AML } \\
\cline { 2 - 5 } & $\begin{array}{c}\text { Theoretical concentration } \\
\mathrm{C}_{\text {theoretical }}, \mu \mathrm{g} / \mathrm{ml}\end{array}$ & $\begin{array}{c}\text { Found concentration } \\
\mathrm{C}_{\mathrm{x}}, \mu \mathrm{g} / \mathrm{ml}\end{array}$ & $\begin{array}{c}\text { Theoretical concentration } \\
\mathrm{C}_{\text {theoretical }}, \mu \mathrm{g} / \mathrm{ml}\end{array}$ & $\begin{array}{c}\text { Found concentration } \\
\mathrm{C}_{\mathrm{x}}, \mu \mathrm{g} / \mathrm{ml}\end{array}$ \\
\hline Control sample & 9.00 & 9.13 & 9.00 & 9.18 \\
Sample P1 & 4.72 & 4.39 & 9.46 & 9.47 \\
Sample P2 & 7.13 & 6.21 & 7.13 & 102.00 \\
\hline
\end{tabular}




\section{References}

1. Koh KK, Quon MJ, Han SH, et al. Additive beneficial effects of AT combined with AML in patients with mild-to-moderate hypertension, Int J Cardiol, 2011, 146:319-325.

2. Blank R, Hobbs FDR, Zamorano J, et al. A single-pill combination of AML besylate and AT calcium (update). Drugs Today. 2007;43(3):157.

3. Liew D, Park HJ, Ko SK. Results of a Markov model analysis to assess the cost-effectiveness of a single tablet of fixed-dose AML and AT for the primary prevention of cardiovascular disease in Korea. Clin Ther. 2009;31(10):2189-2203.

4. Dinç E, Baleanu D. Chemometric simultaneous determination of AT and AML in tablets by PCR and PLS calibrations. Rev Chim-Bucharest. 2009;60(2):127-131.

5. Demirbilek MP, Dinç E, Baleanu D. Spectrophotometric simultaneous determination of AT-amlodipin and telmisartan-hidrochlorothiazide mixtures by bivariate and multivariate calibrations. Rev Chim. 2010;61(6):532-540.

6. Dinç E, Baleanu D. Fractional wavelet transform for the quantitative spectral resolution of the composite signals of the active compounds in a two-component mixture. Comput Math Appl. 2010;59:1701-1708.

7. Petkovska R, Cornett C, Dimitrovska A. Development and validation of rapid resolution RP-HPLC method for simultaneous determination of AT and related compounds by use of chemometrics. Anal Lett. 2008;41(6):992-1009.

8. Abdallah OM, Badawey AM. Derivative-ratio spectrophotometric, chemometric and HPLC validated methods for simultaneous determination of AML and AT in combined dosage form. Int J Ind Chem. 2011;2(2):78-85.

9. Ohannesian L, Streeter AJ. Handbook of Pharmaceutical Analysis. Ed. Marcel Dekker Inc, 2002, 201-238.

10. Estellés ML, Marin Saez R, San Martín Ciges MD, et al. Apparent content curves: description and analytical applications. Resolution of binary mixtures. Fresen J Anal Chem, 1992, 342: 538-546.

11. European Pharmacopoeia, 7th edition, 2011.

12. United States Pharmacopeia 34, 2011.

13. Farmacopeea Română, Ediția a X-a, Editura Medicală București, 1993 